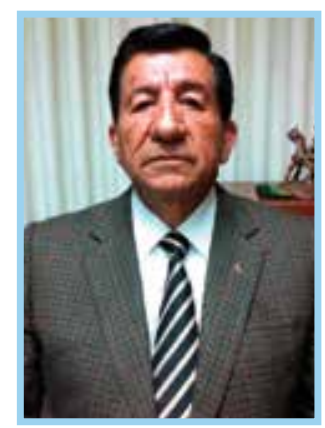

Jorge Silva Merino

\title{
CALIDAD DE LA EDUCACIÓN
}

\section{RESUMEN}

En este artículo se ha tratado de acercarnos al sentido y características que asume el concepto de calidad de la Educación. Para tal propósito, se hace un análisis previo del fenómeno educativo y su relación con los paradigmas; del mismo modo se incluye un ejemplo de los que puede ser la impugnación de paradigmas (revolución científica). Se incluye en el artículo el aspecto de la evaluación de la calidad educativa.

Finalmente, presentamos algunas ideas de ERIC CALCAGNO, Profesor de la Universidad de Buenos Aires, que consideramos apropiadas para trazar el perfil de una educación de calidad.

\section{PALABRAS CLAVE}

Educación, calidad, evaluación.

\section{ABSTRACT}

In this article, it is training to be close of sense and features that take up of quality education concept. To such purpose, an analysis is made previous of education phenomenon and its relation with paradigms (scientific revolution). Education quality evaluation is include in the article.

Finally, we present some ideas from ERIC CALCAGNO, a Buenos Aires University Teacher, which we consider appropiates for desinging a quality of education profile.

\section{KEYWORDS}

Education, quality, evaluation.

\section{INTRODUCCIÓN}

$1 \begin{aligned} & \text { ntes de abordar el tema } \\ & \text { complejo de la calidad de } \\ & \text { la educación, tratemos }\end{aligned}$ de acercarnos al concepto de educación. Desde nuestros años de formación universitaria supimos identificar la educación como fenómeno social, es decir, como acontecimiento que puede verificarse en un espacio y en un tiempo determinado.

Claro que otra pregunta surge de inmediato es ien qué consiste ese acontecimiento o fenómeno? Por supuesto, no podemos responder esta pregunta sin precisar qué elementos intervienen en el proceso.

Trataremos de ilustrar el fenómeno educativo con un ejemplo. Cuando 
vemos un programa de televisión, por lo menos, descubrimos tres elementos básicos: 1) El emisor (que puede o no ser el creador de lo que se transmite; 2) el receptor, que somos todos los que vemos el programa, y 3) el contenido y el propósito de lo que se transmite.

El contenido, lo mismo que el propósito que se pretende, lo determina alguien que tiene poder y autoridad para aprobar el contenido y el uso del medio en que se transmite el contenido (Televisión). Este es uno de los muchos ejemplos que podemos dar sobre el fenómeno educativo; los escenarios pueden ser diversos: la familia, la institución educativa, la calle, los vehículos, el centro de trabajo, la universidad, etc. En cualquier caso, siempre hay alguien que decide lo que se va a transmitir en el acto (fenómeno educativo).

El escenario por excelencia del fenómeno educativo ha sido el hogar familiar y los padres decidían lo que se debía o no transmitir. Esta situación ha cambiado sensiblemente con la creciente y dominante presencia de la televisión primeroyluego del Internet. ¿Cómo competircon estos dos medios que se valen del movimiento, el color, la velocidad y amplitud de las imágenes, lo mismo que el almacén y la repetición ilimitada del contenido que se transmite?

Tanto la institución educativa, a través de los profesores, como los padres de familia, tendrán que aprender, muy rápido a convivir con estas tecnologías, para impedir que trunquen su papel de medios por el de rectores del fenómeno educativo.

Las tecnologías de la información cuyo avance más impactante se ha verificado a finales del siglo anterior y principios de siglo XXI, es probable que sea causa o, por lo menos, variable gravitante de un nuevo modelo de hijo, alumno, de profesor y de padre.

Si ensayamos el concepto de educación como un proceso dinámico de transmisión de la cultura como lo sostiene Gastón Mialaret (1984) en su Diccionario de Ciencias de la Educación. Transmisión de la cultura que se da entre padres - hijos - padres, porque el fenómeno educativo no asume como antes, solo la dirección padre $\rightarrow$ hijo, sino que hoy, con mucha frecuencia, es a la inversa; así como también entre profesor $\rightarrow$ alumno o alumno $\rightarrow$ profesor.

El fenómeno educativo se vuelve más complejo y su impacto es impredecible como desconocida la fuente que aprueba los contenidos que se transmiten y los propósitos que animan a los que deciden cuándo y qué transmitir.

Los modelos o paradigmas educativos propuestos por los científicos de la educación, exigen mucho esfuerzo y compromiso social de las autoridades educacionales para adecuarlos a la realidad nacional, no como consecuencia de la autoridad transitoria de la que están investidos, sino conscientes de que el fenómeno educativo, complejo y dinámico, requiere ajustes periódicos.

Los países han tenido cambios de paradigmas teóricos que no se han plasmado en realizaciones integrales, sólo han devenido en ensayos parciales y, finalmente, fueron abandonados.

Aclaramos que elfenómeno educativo no consiste en la mera transmisión pasiva de la cultura; pues de aceptarlo estaríamos retrocediendo a épocas históricas ya superadas. La trasmisión del contenido cultural, seleccionado por las autoridades competentes con participación de profesores y padres de familia, debe responder al modelo de persona que se pretende formar, a los valores y a los principios, articulados en la visión, misión y modelo educativo, inspirado en la Carta Magna, entendida como la respuesta básica a la estructura social y política que se aspira alcanzar.

\section{La Calidad de la Educación y los Paradigmas}

En este marco, entendemos la calidad como un modelo o arquetipo a ser logrado. De allí la 
exigencia de que, previo a cualquier reforma, se definan la dirección y características del modelo, el cual no sólo debe surgir por canales legales sino, lo que es igualmente importante, ganar legitimidad nacional, por los principios que sustentan al modelo y estructuración de factores que reflejan los distintos actores, escenarios y perspectivas de la realidad nacional sostenible.

Otro ejemplo: el comportamiento de una sociedad será un comportamiento de calidad democrática si ese comportamiento revela características de lo que es una sociedad democrática.

De otro lado, hay quienes sostienen como J. González G. (2004), en su obra "Los paradigmas de la calidad educativa", que calidad es la medida en que algo se aproxima al producto ideal definido históricamente como una realización óptima de lo que le es propio según el género al que pertenece. El ejemplo que se nos ocurre sería el de Acreditación de una Universidad. Así, podríamos afirmar (juicio de valor) que una Universidad es de calidad en la medida que esa Universidad concreta se aproxima al producto ideal definido históricamente como realización óptima, cuyos alcances y características están comprendidas en la Ley y en sus Estatutos.

El paradigma o ideal no es estático, es estructurado por las comunidades científicas y filosóficas correspondientes, en virtud de un estudio serio de la evolución del contexto social, económico y cultural, y es asumido cuando alcanza legitimidad social.

Los paradigmas fueron creados por científicos e intelectuales sin la esperanza de configurar dogmas intocables, más por el contrario, exigen reflexión, contraste de opiniones y reformulación sustentada.

Thomas S. Kuhn (1985), en su obra cumbre: "La Estructura de las Revoluciones Científicas", nos deja una idea de lo que representa un Paradigma: "en su uso establecido, un paradigma es un modelo o patrón aceptado y este aspecto de su significado me ha permitido apropiarme de la palabra ‘paradigma”....agrega Kuhn en la página 51 del libro citado, en gramática, por ejemplo, "amo, amas, amat" es un paradigma, debido a que muestra el patrón o modelo que debe utilizarse para conjugar gran número de otros verbos latinos, v. gr.: para producir "laudo, laudas, laudat".

La idea general de paradigma como la estructura conceptual elaborada por determinadas comunidades científicas para abordar y resolver problemas, es la que más se acomoda al análisis y tratamiento del fenómeno educativo. No es, sin embargo, un modelo o patrón de validez indefinida, por el contrario, las comunidades científicas en base al estudio de la realidad y de la evaluación de los paradigmas pueden cuestionarlos cuando ya no responden a dicha realidad (a este cuestionamiento de paradigmas Kuhn llama revolución científica), lo cual da lugar al surgimiento de nuevos paradigmas.

Algo de lo expresado por Kuhn lo encontramos en el cuestionamiento que hace Pedro Ortiz Cabanillas (2009) en su obra "Educación de la personalidad" cuando se pregunta "de qué manera han contribuido en nuestra formación personal el sicoanálisis, el conductismo, el cognitivismo, sino han sido para acentuar la falta no sólo de productividad y de capacidad de control y dirección", agrega Ortiz diciendo: “iacaso no hemos copiado las formas más groseras de hipersexualidad?, iacaso no somos cuidadosos de las formas de actuar que encubren nuestra informalidad y falta de contenidos?, ¿acaso no se incrementa cada vez más nuestro tiempo de diversión y de las formas de "pasarla bien" en la ociosidad?, zacaso no hemos privilegiado la politiquería y la corrupción en detrimento de la acción política que siempre debió ser esencialmente ética?

Ortiz Cabanillas, luego de criticar a la educación basada en paradigmas exclusivamente tecnológicos, sostiene en las páginas 34 y 35 de su citada obra, que se debe propender a la 
formación integral de la personalidad sustentada en una teoría ética, que el mismo se encarga de sistematizarla en los niveles siguientes:

1. "Una teoría ética filosófica que propugne un modelo de sociedad cabalmente moral, basada en una concepción del hombre acorde con su condición de ser vivo superior".

2. "Una ética científico-social que explique la historia de la inmoralidad y la eficacia de los proyectos teóricos propuestos para la transformación moral de la sociedad, sobre la base de las aspiraciones máximas de solidaridad, libertad y justicia”.

3. "Una ética como tecnología social para el diseño de estrategias educacionales orientadas a la formación moral de la conciencia, con la finalidad de que la persona llegue a ser realmente digna, autónoma e íntegra".

\section{Aprender a pensar y calidad educativa}

Tal vez el aprender a pensar sea uno de los objetivos centrales de todo proceso educativo; si no se logra, se olvida que el hombre puede llegar a ser un manipulador de medios, pero no una personalidad pensante. Flórez Ramiro (1991) en su obra "Razón Educativa", reflexiona de la manera siguiente; "Lo difícil, aunque a la vez lo único fructuoso, es aprender a pensar... $\mathrm{El}$ equívoco que hay que resolver es el de creer que pensar es seguir una sola vía, es decir, la que ha llevado al pensamiento a ocuparse con la ciencia y con la técnica como ramas desgajadas del árbol del filosofar, y que sin embargo en ellas ya no pueda ejercitarse el pensar..." (p. 113).

\section{EVALUACIÓN DE LA CALIDAD EDUCATIVA}

Entendemos a la evaluación como los juicios de valor que surgen de comparar un objeto, proceso, competencia, rendimiento académico, sistema educativo, sistema formativo, etc., con determinados criterios de valor o de calidad, a fin de tomar decisiones generales o procesales, en el marco del paradigma que sustenta el sistema educativo como un todo o de sus partes.

En este sentido, la calidad se ha entendido como la correspondencia entre hacer algo y lo que ese algo es. Por ejemplo, el niño tendrá una lectura de calidad si el acto de leer a su cargo responde a las características propias de una lectura de calidad.

En el proceso de evaluación de la calidad de la educación y en el marco de los ejes de evaluación que desarrollaron A. Medina Rivilla A. y María Luisa Sevillano García 1997), hay que distinguir el objeto de la evaluación, los extremos descriptivos, los referentes normativos y la calidad de la toma de las decisiones.

Cuando nos referimos al objeto de la evaluación estamos pensando en una variedad de posibilidades, por ejemplo: podemos evaluar la calidad de algo material como las características funcionales de un ordenador o computador; la calidad de las copias o impresiones de una impresora; la calidad de una biblioteca; la calidad del campus de una universidad, etc.; también podemos evaluar la calidad de la gestión institucional, el ordenamiento organizativo.

Enelorden personalpodemos evaluar la eficiencia personal de dirección institucional; la calidad de las competencias laborales o profesionales; la calidad del rendimiento académico de los estudiantes o de las competencias pedagógicas de los docentes, etc.

Para evaluar la calidad de la educación necesitamos considerar los extremos descriptivos, así, en algunos casos se tendrá que recurrir a la medición y en otros al polo opuesto de la estimación. Se puede medir el porcentaje de asistencias de un estudiante a sus labores académicas; también puede medirse la velocidad 
de un estudiante en su capacidad de lectura o el número de errores en la pronunciación de las palabras.

De otro lado, habrá aspectos que no se pueden medirtales comoel espíritu crítico, la sensibilidad humana, la solidaridad social o la coherencia del comportamiento personal, entonces hay que recurrir al polo opuesto de la estimación o apreciación que, desde luego su falta de precisión en el juicio evaluativo se compensará largamente, con la finura cualitativa.

La medición y la apreciación nos ofrecerán información sobre el objeto que se evalúa con tanta validez y confiabilidad como válidos y confiables resulten los instrumentos de extracción de información.

Los referentes normativos pueden, igualmente, asumir dos extremos: de un lado se puede evaluar con referencia estadística, es decir, comparar el nivel de aprendizaje de un determinado estudiante con el promedio de calificaciones del grupo al que pertenece.

El otro extremo sería evaluar con referencia a un determinado criterio, es decir, aquí la comprobación del rendimiento académico de un estudiante se hace respecto de un determinado nivel y características propias de una disciplina o proyecto de aprendizaje.

El estudiante no mirará el rendimiento de su grupo sino a la evolución del ritmo de su propio progreso personal y las exigencias de la disciplina o del proyecto, como criterio de evaluación.

Finalmente, la toma de decisiones que algunos autores y docentes no consideran parte de la evaluación propiamente dicha, sino del proceso educativo en su conjunto, consistiría en las decisiones que adopta el docente para regular el proceso de enseñanza aprendizaje y motivar el rendimiento responsable del estudiante. Cumple, de esta manera, una función retro alimentadora.
La evaluación así diseñada puede contribuir al logro progresivo y sustentado de la calidad educativa, sobretodo aquella evaluación en base a criterio, en la cual cada estudiante tiene su propio reto, incrementar su aprendizaje, sin tener que compararse con sus pares, sino consigo mismo, con lo cual estaría educando su autodeterminación y su autoevaluación.

\section{Conclusiones}

A modo de corolario o de conclusiones listamos algunas ideas para lo que puede ser el perfil de una educación de calidad, propuesto por Eric Calcagno (Profesor de la Universidad de Buenos Aires):

1. Lograr una formación como persona total, desde sus intereses, su singularidad y autonomía, su aceptación y autoestima.

2. Aceptar la formación permanente como una línea constante y progresiva que vincule en forma dinámica el conocimiento, la experiencia y la autoformación.

3. Tener una actitud crítica sobre su acción, de forma reflexiva y siempre abierta al cambio.

4. Abordar permanentemente nuevos contenidos, conceptos y teorías de las ciencias y temáticas que deban enseñar, atendiendo a la integración dinámica que se da hoy entre las disciplinas.

5. Estar preparado para decodificar, filtrar e interpretar la multiplicidad de mensajes que se reciben por los diferentes medios de comunicación.

6. Entablar una relación pedagógica basada en el diálogo franco y transparente y en el respeto mutuo, con disposición y habilidad para administrar las tensiones, los conflictos y los momentos de armonía. 
7. Investigar otros modelos o paradigmas de aprendizaje, saber cómo se "aprende a comprender", reconocer cuándo no se aprende, modificar si son necesarios los esquemas adquiridos durante su formación inicial, apoyándose en fundamentos teóricos, que deberá integrar dinámicamente con sus saberes previos.

\section{REFERENCIAS}

Calcagno, E. (2001). Apuntes sobre ideas educacionales para el siglo XXI. Manuscrito inédito preparado por J. Silva M. Perú: UNIFÉ.

Flórez, R. (1991). Razón Educativa. Madrid: Fundación Universitaria Española.

González, J. y otros (2004). Los paradigmas de la calidad educativa. De la autoevaluación a la acreditación. México: Unión de Universidades de América Latina, A. C.

Kuhn, T. S. (1985). La estructura de las revoluciones científicas. México: Fondo de Cultura Económica.
8. Estar abierto a los aportes de la educación no formal, a la vida cultural de la comunidad donde está inserto su centro educativo; siendo permeable al impacto de los valores predominantes del entorno social económico y religioso, frente a lo cual el proceso educativo debe enfatizar las fortalezas y propiciar la superación de sus debilidades, cuando éstas resulten esenciales para el desarrollo humano y de la sociedad.
Medina, R. y Sevillano, G. L. (1997). Didáctica-ElCurriculum: Fundamentos, Diseño, Desarrollo y Evaluación. Madrid: Impressa Ediciones.

Mialaret, G. (1984). Diccionario de Ciencias de la educación. Barcelona: Oikos - Tau, S. A. Ediciones.

Ortiz, P. (2009). Educación y formación de la personalidad. Lima: Fondo Editorial de la Universidad de Ciencias y Humanidades. 